\title{
Comments Re: Draft Regulatory Guide for Release of Patients Administered Radioactive Material Docket ID NRC-2019-0154
}

\author{
Jeffry A. Siegel
}

Nuclear Physics Enterprises

$\mathbf{T}$ he U.S. Nuclear Regulatory Commission (NRC) has issued for public comment draft regulatory guide (DG), DG-8057, "Release of Patients Administered Radioactive Material." This is a proposed Revision 1 to Regulatory Guide 8.39.

For years, the NRC has periodically asked for comments regarding their patient release guidance, even though for the most part these comments have been continually ignored. Now, they are unashamedly asking for comments yet again. This has been going on nonstop for more than 20 y since 1997. First, there was Regulatory Guide 8.39 followed by 3 versions of Appendix U in NUREG-1556, vol. 9, and now this guide 22 y later (rehash \#5, dubbed Revision 1 of Regulatory Guide 8.39). Despite all the literature evidence to challenge and call for change, this guidance has changed minimally, remaining devoid of scientific rigor and essentially fatally flawed. I have published more than 30 articles documenting what is wrong with NRC's patient release guidance (the rule pursuant to 35.75 is fine) and sent letters to staff and the Commission in an effort to put an end to this nonscientific saga. None of this, nor any other peerreviewed publications, has influenced the NRC to end its cycle of asking for comments over and over again, let alone using this information to redo its guidance correctly or better yet, withdrawing it altogether. A paltry few of us have been trying for more than 2 decades now, but the vast majority of putative experts have remained essentially silent and continue to just accept the guidance.

The NRC's Advisory Committee on the Medical Uses of Isotopes (ACMUI) published its "Patient Release Report" on December 13, 2010, indicating that NRC guidance overestimates doses and recommended that it be updated with assistance from experts. Interestingly, NRC staff apparently disagreed with the ACMUI and my numerous publications. They not only did not seek expert assistance but also importantly asserted that overconservatism is appropriate and that any criticism of this practice "reflects a misunderstanding of the guidance." This latter assertion, however, is backwards - the guidance, in fact, reflects a misunderstanding of compliance with the 35.75 requirement- there is nothing in the regulations that mandates that likely doses to others be massively overestimated based on assumptions and calculational methods known to be false. Unfortunately, even though guidance carries no regulatory

Received Sep. 30, 2019; revision accepted Sep. 30, 2019.

For correspondence contact: Jeffry A. Siegel, Nuclear Physics Enterprises,

4 Wedgewood Dr., Marlton, NJ 08053.

E-mail: nukephysics@comcast.net

Published online Oct. 4, 2019.

COPYRIGHT (C) 2019 by the Society of Nuclear Medicine and Molecular Imaging.

DOI: 10.2967/jnumed.119.237552 weight, most licensees adopt it anyway without critical assessment, thereby adding an unfounded extraregulatory burden, which in this case, is totally baseless.

The NRC believes the affected licensees need their guidance; and perhaps they are right, that is, they believe many of their licensees do not have the requisite training and experience (despite all codified requirements) to perform their own calculations to comply with the patient release rule (10 CFR 35.75). According to SECY-12-0011, Data Collection Regarding Patient Release, dated January 25, 2012, "The calculations performed by NRC and described in the NUREG, and the tables that are based on these calculations, are intended to serve as screening tools for the convenience of licensees who may not wish to do their own calculations, or who do not have the technical expertise to do them [emphasis added]." NRC apparently believes it is just fine if their licensees do not want to do calculations or worse yet, cannot. If this is indeed true, and licensees are using the patient release guidance to comply with 10 CFR 35.75, perhaps they should not be authorized to treat patients. At the very least, these licensees should be educated (not by NRC or by anyone they may recommend) so they can end their reliance on this guidance and implement standard operating procedures to effectively and correctly comply with the patient release rule.

The NRC keeps doing the same thing, but importantly, we, the regulated community, let them - if this continues, change will never occur. We need all those claiming to be radiation safety experts to send in comments-NRC has to be continually overwhelmed with comments to end this guidance. We can no longer sit idly by and continue to accept this inaccurate nonscientific approach. There needs to be an orchestrated pushback effort, acknowledging NRC's apparent lack of expertise in this area. It's been $22 \mathrm{y}$; how much longer will the regulated community remain silent and let the NRC get away with this?

\section{DISCLOSURE}

No potential conflict of interest relevant to this article was reported. 